\title{
DIRECTIONS AND PRIORITIES FOR SUSTAINABLE DEVELOPMENT OF GRAPE-WINE SECTOR IN BULGARIA
}

\author{
A. Miteva*, Iv. Kanchev \\ Economy of Natural Resources Department, UNWE, Sofia, Bulgaria
}

\begin{abstract}
Vine-growing and wine making are one of the sectors of agriculture for which the problems of management of marketing and sustainable development have a specific manifestation. A prerequisite for this are the peculiarities of viticulture and the production and trade of wine and other products from the processing of grapes.

The purpose of the report is on the basis of the assessment of the state and the current development of the potential of the wine sector to define the main directions and priorities for achieving the criteria of the National Strategy for Development of Production and Trade with Wine aiming its transformation into a leading sector of the national economy.

In the report are depicted the measures related to creating conditions for accelerating the pace of planting new vineyards, for consolidation of vineyards, for implementation of innovative solutions and good world practices for wine and grape production.

A place in the report will find also the justification of the main directions and proposals for the development of the organizational structures for grape and wine production, including the forms for cooperation and integration between the companies in order to build cluster formations for implementing wine tourism and other modern forms for production and marketing of wine.
\end{abstract}

Key words: grape-wine sector, sustainable development, National Strategy for Development of Production and Trade with Wine

\section{INTRODUCTION}

Vine-growing is one of the sectors of agriculture for which the problems of marketing management and sustainable development have a specific manifestation. A prerequisite for this are the peculiarities of viticulture and the production and trade with wine and other products from the processing of grapes.

The purpose of the report is on the basis of the assessment of the state of the current development and the potential of the wine sector to propose the main directions and priorities for achieving the criteria of the National Strategy for Development of Wine Production and Trade with a view to its transformation into a leading sector of the national economy.

In the paper are elaborated and evaluated the measures related to the creation of conditions and prerequisites for accelerating the pace of

\footnotetext{
*Correspondence to: Albena Miteva, Sofia, UNWE, Economy of Natural Resources Department, tel: 0888 869620, e-mail: albenakm@yahoo.com
}

establishment of new vineyards, for consolidation of vineyards, implementation of innovative solutions and good world practices for grape and wine production.

\section{METHODS}

Company brand policy in Wine Production The wine industry is heavily influenced by the globalization that leads to oversupply in the sector. This necessitates a differentiated approach to serving the markets by applying an individual company brand policy. The implementation of this policy is based on the right choice of production and other factors (grape variety, region of production, established firm - producer, etc.) that identify the appearance of the final product the identity of the produced mark. Looking for the identity of their brands, manufacturers apply agrotechnical and environmental practices and combine them in a suitable combination to ensure that their production meets market expectations.

In practice, this leads to the creation and construction of company brand wines, which embodies the achievement of wine production with new, better quality using and utilizing 
efficiently the available natural and other assets of the individual wine regions. A new quality is sought with regard to the taste and aroma characteristics of wine, which are preferred by its consumers.

The branding policy has a complex character which requires the main business activities to be taken into account as well as the characteristics of the cultivated wine grape varieties and the characteristics of the region in which the production activity takes place. These peculiarities are at the heart of integrating wine cellars with grape growers from a particular region, and are also one of the reasons for the creation of wine cellars with their own vineyards. In this way it is easier to form the market image of the companies and brands of high quality wines with a controlled designation of origin and a declared geographical region. The names of wines associated with places known as traditional wine-growing centers are known for the production of limited quantities of unique wines. They are made from varieties with a denomination that have a specific quality that causes associations in consumers to prefer them when choosing a wine to purchase.

The smart use of wine designations of origin is part of the application of the marketing approach that gives consumers a guarantee and becomes an important motivator for preferring one brand of wine to another.

In defining wine identity, the French Terroir Concept also contributes to be taken into account the specific features that the geographical region and the soil type positively influence the quality of the wine. The essence of the terroir is limited to the place where the vine is grown, which includes, besides a suitable soil type and a local environment with its specific characteristics, which give a unique quality to the product - the wine. Bulgaria has very good soil and other specific conditions for winemaking, so the development of terroir wines in our country has a definite future. These are the regions of the Southeast Thracian Plain (Harmanli, Haskovo, Ivaylovgrad), the Black Sea region / Bourgas, Pomorie, Aitos /, Varna and Svishtov regions and others.

In this aspect, benefits can also be gained from wine tourism organized within a separate winery or specific wine region. This type of tourism increasingly attracts the attention of a wider range of consumers and converts him into a specific marketing approach for imposing firm products on the market.
It can be summed up that the company's marketing policy in the wine-making sector of Bulgaria is in practice aiming at the sustainable development of the wine sector, and in particular looking for persistence in the quality of the produced wines which form the brand of wines of the individual producer, thus alleviating their distinction from those of its competitors.

\section{RESULTS}

1. Assessment of the state and development of the potential of the wine sector

After the accession of Bulgaria to the EU and to the European wine market, new opportunities for development of the wine sector in our country were opened. With the implementation of the CAP of the EU, quality requirements have also been upgraded to ensure competitive production and sustainable development of the wine sector, taking greater environmental protection requirements.

Under modern market conditions, wine production in Bulgaria is a largely exportoriented sector significantly dependent on world wine trade. Under these conditions, the management of the marketing activity of the sector is much more determined by the demand for wine both on the world markets and by the traditional consumption on the Bulgarian market. This necessitates extensive market research of the demanded wines, a change in the wine varieties structure, changes in the size of the areas and accelerated application of new technologies and progressive marketing practices for the realization of finished products.

The analysis of the state and of the potential opportunities for development of the wine sector can be adequate to the contemporary challenges when it is developed by periods, with the base being adopted 2000 when ended the structural reform of the agrarian sector in our country, including in the viticulture and wine sector. The next period in the development of the sector started in 2007 with the accession of our country to the EU, namely the periods /2012/2015 / and /2015-2019/ when began the implementation of the first and second National Programs for Wine Sector Development.

These analyzed periods take into account the main trends and changes in the areas and yields of the vineyards, as well as in the production of grapes and wine. 
The total area of vines over the last 8 years within the EU is decreasing. This is due to the implementation of the new Community regulations related to the conversion and eradication of vine plantations. The same tendency to reduce the area of vineyards is typical for Bulgaria. The data on the area of the vineyards for the period 2000-2015 (Table 1) shows that the decline continues and it is due to the increasing unserved vineyards and the continuing practice of abandoning the vineyards and increasing the area of the nonfertile vineyards.

Table 1. Area of the vineyards in Bulgaria for the period $2000-2015$ (ha)

\begin{tabular}{|l|l|l|l|l|}
\hline Years & Served & |Unserved & Total & $\begin{array}{l}\text { Area dynamics in\% } \\
\text { (base 2000) }\end{array}$ \\
\hline $\mathbf{2 0 0 0}$ & 153200 & 7271 & 160471 & 100 \\
\hline $\mathbf{2 0 0 7}$ & 97387 & 22954 & 120341 & 75 \\
\hline $\mathbf{2 0 1 3}$ & 58236 & 4900 & 63136 & 39 \\
\hline $\mathbf{2 0 1 4}$ & 52587 & 10298 & 62885 & 39 \\
\hline $\mathbf{2 0 1 5}$ & 50705 & 12086 & 62791 & 39 \\
\hline
\end{tabular}

Source: NSI, Agrostatistics

Wine varieties have a dominant role in the structure of the maintained vineyards, due to the growing interest in the process of restoration of vineyard varieties and the increasing interest of growers in planting of new vines that are regulated by the Ordinance on Terms and Conditions for Planting Vines for Replanting, Grafting and for Eradicating existing ones. Low fluctuations in the structure of red and white wine varieties are observed for the analyzed period. Red wine varieties dominate, with an increase in the share of white wine varieties in the last few years.

In terms of average yields, data show variations in years for wine varieties. This is due to the technologies used for growing the vine and soil-climatic changes, as well as to the non-observance of the growing technology. The good climatic conditions, the compliance with the agro-technical measures in the cultivation of wine varieties are the cause in some years (2006, 2007 and 2013) the average yields to be lower than the average annual level and the unfavorable climatic conditions are the reason for the lower yield in 2014.

Concerning the world grape production after 2000, weak fluctuations are observed. Unlike this tendency, in Bulgaria there is a decrease in the total quantities of produced grapes (Table 2), which is mainly due to the reduction of the areas under vines. The dynamics of production shows that least are the quantities of grapes produced in 2005 and 2006 and 2014.For the years 2005 and 2014 this is due both to the reduction of the areas under vines and to the low average yields. Regardless of the difference in average yields and the reduction of the area, the structure of the grape production is kept the same during the analyzed period and the wine vine varieties are about $95 \%$.

Table 2. Grape production in Bulgaria for the period 2001-2015

\begin{tabular}{|l|l|l|l|l|}
\hline \multirow{2}{*}{ Years } & \multicolumn{2}{|l|}{$\begin{array}{l}\text { Distribution of the grapes produced, } \\
\text { thous.kg }\end{array}$} & \multirow{2}{*}{$\begin{array}{l}\text { Production dynamics } \\
\text { in\% (base 2001) }\end{array}$} \\
\cline { 2 - 5 } & $\begin{array}{l}\text { From } \\
\text { vineyards }\end{array}$ & $\begin{array}{l}\text { Production } \\
\text { dynamics in\% } \\
\text { (base 2001) }\end{array}$ & Total & \\
\hline $\mathbf{2 0 0 1}$ & 431480 & 2018 & 433498 & 100 \\
\hline $\mathbf{2 0 0 7}$ & 355459 & 21204 & 376663 & 87 \\
\hline $\mathbf{2 0 1 3}$ & 304090 & 21506 & 325596 & 75 \\
\hline $\mathbf{2 0 1 4}$ & 123912 & 8819 & 132731 & 30 \\
\hline $\mathbf{2 0 1 5}$ & 242936 & 18884 & 261820 & 60 \\
\hline Average for the period & 249752 & 13447 & 263198 & - \\
\hline
\end{tabular}

Source: NSI, Agrostatistics

Between 2001 and 2015, slight fluctuations in the structure of processed and consumed grapes were observed, with an average of $90 \%$ of grape processed into wine and other products and about $10 \%$ of grape for direct 
consumption. Differences in the structure of the processed grapes show sharp fluctuations in the relative shares during the period 20002015. In some years, the quantity of processed grapes in industrial conditions is equal to those processed at home (2001, 2002), and in others, the relative shares vary about nine times (2005). The distribution of industrially produced wine according to the color for the period 2003-2012 shows that red and pink wine types are slightly overwhelming due to the wide distribution and traditions in the production of red wine. From the beginning of the period, the quantities of red and pink wines decreased by $20 \%$ and white wines increased significantly. This is due to the tendency for white wines to find a better reception on international wine markets.

In the studied areas the vineyards of the farms have different specialization and organizational status, with the highest relative share being the holdings of individuals. The majority of family grape-growing holdings are registered as farmers and as single area payment applicants, ie they operate as market and semi-subsistence farms. The survey shows that farms registered by the National Grape-Wine Chamber are fewer than half of the grape-growing farms registered as agricultural producers. Even less are the declared grape growers with the Executive Agency for Vine and Wine, most of which are registered under the Commerce Act. The reason for the large differences between the three types of registrations are the established parameters for the lower limit and the size of the vineyards of the holdings of individuals and legal entities, as well as the insufficient awareness of the producers about the opportunities that their registration as vinegrowing farms gives. Another reason is the insufficient impact that the measures of the applied CAP have on the increase of the incomes of the vine growers.

A characteristic feature of the viticulture sector is its seasonality in the use of labor force and technical means. It stems from the biological characteristics of the vine and the agrotechnological process, which determine the peculiarities of the use of permanent and temporary workers in the sector. They are sharply changing in number and seasons of the year according to the applied technology and organization of production. In addition, the over-50s age group predominates among the hired workers in most of the regions. This imposes on these growers the need to create in the vineyard farms additional and accompanying activities in order to increase the annual employment of the hired workers.

\section{Trends and problems of the functioning of the wine-growing enterprises}

On the basis of analysis of the distribution, characteristics and problems of the wineproducing enterprises, the following trends and problems in their functioning and development are outlined:

- There are various forms of organization of wine production and realization that have an impact on rural development. The most significant impact on income growth and the improvement of the social situation of the inhabitants of the regions have the cooperatives and companies owning their own enterprises and own vineyards established in recent years.

- Only newly built wineries, and especially those who have introduced technological lines for deep processing of waste from the main production of grapes and wine, contribute to the protection of the environment

- Wine cellars that buy production from farmers in the region do not have a lasting relationship with the them and with producers of raw materials from other regions.

- All tested manufacturers have problems with the realization of the production. Depending on their assortment, these problems are more pronounced in those, producing relatively younger wines and of lower price groups.

The general assessment of the wine sector, based on the SWOT analysis, shows the main features and trends in the sector development by assessing its strengths and weaknesses and potential development potential.

The results of this analysis show that the strengths of viticulture and wine-making are related to the centuries-old traditions of viticulture / created unique local wine and dessert grape varieties/, and in wine production - with the applied local technologies and unique combinations of soil and climatic factors of the wine regions, linked with the specific qualities of wines made from local grape varieties and unique hybrid varieties, a product of ancient and modern selection.

In the field of wine-making, the image is given to it by more than 50 large wine-producing companies evenly distributed throughout the country. They are the basis for the promotion and distribution of wines in traditional and new markets, as well as the availability of highly qualified experts and scientific staff from research institutes, and a well-balanced law on wine and alcoholic beverages. 
The characteristics that determine the weaknesses of wine production in Bulgaria are due to: the aggravated age structure of the vineyards, the small size of the vineyards, the insufficient knowledge for accelerated implementation of modern technologies in viticulture and wine production, and the poor market orientation of the wine trade by local varieties of grapes, as well as the insufficient national financing of viticulture and the lack of promotion of Bulgarian wines on the foreign markets.

The analysis of the opportunities and threats for the development of the sector, based on the conclusions of the strategic analyzes of the internal and external environment, determine the insufficiently used opportunities for conquering new markets for bio and delicate products, diversifying the preferences of the consumers and on this basis positioning new brand wines as well as exploiting the opportunities of globalization of the wine market through exchange of specialists and technologies, access to information and development of wine tourism.

The characteristics that describe the threats of wine producers in Bulgaria are also related to climate change, environmental pollution, small size of vineyards, slow pace of renovation of vineyards, etc.

\section{CONCLUSION}

\section{Guidelines and proposals for the development of organizational structures for production of grapes and wine.}

On the basis of the analysis of the distribution, characteristics and problems of the wineproducing enterprises, the main directions of their organizational strengthening and sustainable development are outlined. In addition, the existing forms of organization of wine production and trade have a direct impact on the development of the rural areas in which they are located. Generally speaking, the differences between the studied different models of the wine-producing enterprises include a variety of production units along the chain from raw material production to the final product. The most prominent are the organizational structural units with scope of activity processing of raw materials and wine trade. Some of these enterprises do not have their own raw material and buy from holdings of individuals and legal entities. Their main problem is the realization of finished products. In order to overcome this weakness, it is necessary for them to set in their strategy the accelerated construction of their own distribution networks to sell the finished products, including the available quantities of obsolete production. These enterprises also have the potential to buy land for the creation of their own vineyards. This will help to overcome their current insecurity in providing the necessary amount of grapes for the production of wines of established origin and brand.

Another important milestone in overcoming the existing difficulties with the raw material is the possibility of creating contractual associations with the grape growers or their organizations.

The cooperative and vertically integrated companies of wine growers have the most significant impact on raising income and improving the social situation of rural residents. Their members - the grape growers have more motivation as independent winemakers. Their raw material is of controlled quality and is obtained using modern technological solutions from controlled certified seedlings.

A progressive form of organization at this stage of a wine-making enterprise are the wineries with a complete production cycle. These organizational structures carry out selfproduction of raw material of controlled quality. They also execute a diversification of the main activity by creating other additional activities such as organizing hotel and restaurant activities, wine tasting combined with wine tourism and participation in the Wine Roads under the form of specialized tourist destinations.

Closed-production cycle wineries introduce new technological solutions related to deep processing of residual products from the main production process. The main directions for the development of these wine-producing enterprises is the development of long-term programs that suggest their inclusion in various cluster formations through the implementation of additional activities and tourist destinations such as wine spa procedures, health programs using the products of wine making.

Another possibility to overcome part of the problems of the producers of grapes and wine in the wine-growing regions is the establishment of producer organizations. They are a suitable form to associate small grape growers with wine cellars that have small vineyards or do not have their own vineyards. Producer organizations also play an important role in stabilizing the production of raw materials and in improving the market position 
MITEVA A., et al.

of wine producers. This integration of farmers makes it possible to realize the classical advantages of consolidated production and supply. In this case, this means supplying larger quantities of grapes of one species and variety, achieving a better market price and reducing production costs while improving the quality of the production.

Inter-enterprise cooperation and the establishment of inter-cooperative unions and organizational chains with the participation of $\mathrm{R} \& \mathrm{D}$ structures are one of the possibilities for the development of cluster organizations. They should be based on general or auxiliary products, production processes associated with separate technologies, appropriate natural resources, and the availability of qualified labor potential. The range of cluster entities is largely determined by the time and distances that founders are willing to travel to ensure employment for the local population.

A key advantage of cluster organizations is that they produce secondary effects that generate larger company's resources, greater variety and lower supply prices, availability of specialized services, skilled labor, and potential partners. All this contributes to alleviated access to new technologies, to untapped markets and to greater employment opportunities in the regions.

On the basis of the general principles for the creation of cluster formations there are also significant advantages of creating a specialized Wine Tourism cluster. Its advantages are disclosed in the analysis of the advantages of the sector related not only to the good structure of the vine plantations but also to the national chauvinism regarding the consumption of local wines. These areas also feature the development of a significant number of relatively small wineries producing a wide range of quality wines with controlled and guaranteed origins. A relatively large number of small wineries participation is also characteristic of the cluster. Last but not least, the motivation for developing such a cluster is also the growing number of foreign tourists in our country, especially from neighboring countries.

In conclusion, it can be concluded that viticulture and wine production are traditionally developed sectors of the Bulgarian economy. The presence of the potential of local and selected varieties and distinct wine-growing regions combined with qualified human resource and modern material and technical facilities are conditions for achieving a new production and market orientation of the trade with quality wines and the fulfillment of the criteria of the National Development Strategy for production and marketing of wine.

\section{REFERENCES}

1. Ivanov B, Radev T., Borisov P., „Development and assessment of grapevine sector sustainability", Publishers. Avangard Prima, Sofia, 2012

2. Jelev S. Marketing research, Publishers Trakia, 2002

3. Law in wine and alcoholic beverages, State Gazette. No.45/15.06.2012.

4. Kirechev D, „Investment process in viticulture sector in Bulgaria", thesis, 2013.

5. Kanchev I, Miteva A, The reform in the grape-wine sector, published in „The world crisis and the economic development", vol. 3. Varna, 2010

6. Borisov P., Specialization of Vine-Growing in South Bulgaria. Journal of Wine Research, 2007

7. European Union Food Sector after the last enlargements - conclusions for the future CAP, Warsaw, 2011.

8. Keller, K. Strategic brand management: Building, Measuring and Managing Brand Equity N.J. 1998.

9. Kotler Ph., B2B Brand Management, Springer, 2006 